\title{
Family History, Consanguinity and Other Risk Factors Affecting the Prevalence of Prediabetes and Undiagnosed Diabetes Mellitus in Overweight and Obese Yemeni Adults
}

\author{
Butheinah A Al-Sharafi (D) \\ Ahmed A Qais' \\ Khalil Salem ${ }^{2}$ \\ Muneer $\bigcirc$ Bashaaib $^{2}$ \\ 'Department of Internal Medicine, \\ School of Medicine and Health Sciences, \\ Sana'a University, Sana'a, Yemen; \\ ${ }^{2}$ Department of Internal Medicine, \\ University of Science and Technology \\ Hospital, Sana'a, Yemen
}

\begin{abstract}
Objective: Overweight and obese adults are at high risk for developing prediabetes and diabetes. The aim of this study was to measure the prevalence of prediabetes (pre-DM) and diabetes (DM) among Yemeni adults who were overweight or obese and had first-degree relatives with DM, consanguinity and other risk factors.

Patients and Methods: This cross-sectional study included 612 adults, all with a BMI $\geq 25 \mathrm{~kg} /$ $\mathrm{m}^{2}$. BMI, blood pressure (BP) and waist circumference (WC) were measured in the clinic. Fasting blood glucose (FBG) was collected for all subjects. The patients either had first-degree relatives with diabetes or not, and the subjects answered a questionnaire regarding the consanguinity of their parents, exercise, khat chewing, smoking, and eating vegetables and fruits daily. Results: Of the 612 study participants (32\% males and 68\% females) aged 20-70 years old, $429(70.1 \%)$ had a family history (FM) of DM \pm consanguinity of parents, and $183(29.9 \%)$ had no FM of diabetes. Multivariate analysis showed significant risk in those with class III obesity for pre-DM (AOR 3.10 95\% CI 1.56-6.18 p value 0.001) and DM (AOR 3.35 95\% CI 1.47-7.65 p value 0.004) and those who had siblings with DM had a risk for pre-DM (AOR 1.72 95\% CI 1.09-2.71 p value 0.02) and DM (AOR 2.24 95\% CI 1.25-4.0 p value 0.007). Khat chewing increased the risk for pre-DM (AOR 1.61 95\% CI 1.04-2.48 p value 0.032) and for DM (AOR 2.09 95\% CI 1.14-3.82 p value 0.017). Having consanguineous parents plus siblings with DM were associated with a higher risk of DM ( $p$ value 0.031 ).

Conclusion: There is a high prevalence of pre-DM and undiagnosed DM among overweight and obese Yemeni individuals. Class III obesity, having siblings with DM, chewing khat, and having consanguineous parents plus siblings with DM all increased the risk. This group should be screened at an early age for early detection of pre-DM and DM.
\end{abstract}

Keywords: Yemen, prediabetes, diabetes, prevalence, overweight, obese, consanguinity, khat-chewing

\section{Introduction}

Diabetes mellitus is a group of metabolic disorders with different etiologies defined by elevated glucose levels in the serum or persistent hyperglycemia. It involves abnormal insulin action, secretion or both. ${ }^{1}$ Type $2 \mathrm{DM}$ is a very common form of the disease, has been predicted to be a heterogeneous group of metabolic and multifactorial disorders and is associated with serious complications that affect the lifespan and quality of life. ${ }^{2}$ Pre-DM and type 2 DM are increasing in prevalence worldwide. The International Diabetes Federation (IDF) estimates that
Correspondence: Butheinah A Al-Sharafi Email balsharafi@hotmail.com 
a total of 463 million people have diabetes worldwide. This number is predicted to increase to 454 million $(8.0 \%)$ by 2030 and 548 million $(8.6 \%)$ by $2045 .^{3}$ Additionally, it is estimated that globally, $50 \%$ of people with diabetes are unaware of their condition. ${ }^{3,4}$ The estimated number of adults aged 20-79 years with impaired glucose tolerance is 374 million $(7.5 \%$ of the world population in this age group). The importance of impaired glucose tolerance (IGT) and impaired fasting glucose (IFG) is that they signify a risk of developing type 2 diabetes, and their detection can lead to interventions that can help prevent type $2 \mathrm{DM}^{3}$ Progression from prediabetes to type 2 diabetes is linked to the severity of hyperglycemia and associated with risk factors such as age and weight. The cumulative incidence of type 2 diabetes progression five years after diagnosis of IGT or IFG is estimated to be between $26 \%$ and $50 \%$, respectively. ${ }^{3}$ The American Diabetes Association (ADA) advises screening at any age in adults with a $\mathrm{BMI} \geq 25$ with any of the following risk factors: first-degree relative with diabetes; high-risk race/ethnicity; history of cardiovascular disease; hypertension $(140 / 90 \mathrm{mmHg}$ or on therapy for hypertension); HDL cholesterol level $<35 \mathrm{mg} / \mathrm{dL}(0.90 \mathrm{mmol} / \mathrm{L})$ and/or a triglyceride level $>250 \mathrm{mg} / \mathrm{dL}(2.82 \mathrm{mmol} / \mathrm{L})$; women with polycystic ovary syndrome; and physical inactivity and other clinical conditions associated with insulin resistance. ${ }^{5}$ No recent studies have been performed in adults in Yemen on the prevalence of pre-DM and type 2 DM among overweight and obese adults. The aim of our study was to estimate the prevalence of pre-DM and undiagnosed type 2 DM among overweight and obese first-degree relatives of patients with type $2 \mathrm{DM}$ and among those who had consanguineous parents. This information was recorded in addition to assessing other risk factors leading to pre-DM and type 2 DM among those with a $\mathrm{BMI} \geq 25$ by measuring the FBG and in those with an impaired FBG to perform an oral glucose tolerance test (OGTT) or with an FBG $\geq 126 \mathrm{mg} / \mathrm{dL}$. The HBA1c was also measured.

\section{Patients and Methods}

This is a cross-sectional study that was performed at 3 different centers in Sana'a, Yemen, from May 2019 to July 2021. The majority of the subjects were seen in a private endocrinology and diabetes center, the accompanying relatives coming with patients with type 2 diabetes were asked to participate, and posters were put up in the clinic encouraging participation in the study. A smaller number was seen at the University of Science and Technology Hospital and Ibn Sina Hospital. All the patients were asked to answer a questionnaire, and an FBG was measured. Written informed consent was obtained from all the subjects. A total of 612 overweight and obese subjects aged 20-70 years volunteered to enroll in the study (all the subjects included in the study had no history of hyperglycemia or DM in the past, and those who had a history of hyperglycemia or DM were excluded from the study). Fasting glucose levels were measured by a blood draw (196 males and 416 females). The subjects were divided into 2 groups:

Group 1: the control group was overweight or obese adults aged $\geq 20$ years with no first-degree relatives with diabetes $(\mathrm{N}=183)$

Group 2: overweight and obese adults aged $\geq 20$ with one first degree relative or more with type 2 diabetes $(\mathrm{N}=429)$

These groups were further divided into the following sub-groups

(a) Having 1 parent \pm siblings with type 2 diabetes

(b) Having 2 parents \pm sibling with type 2 diabetes

(c) Having 2 parents that were related \pm siblings with type 2 diabetes (the degree of consanguinity was not discussed in detail, just if the parents were related or not)

(d) Having siblings only with type 2 diabetes

All the subjects were asked to complete a questionnaire regarding their family history, history of exercise at least 30 minutes per day, history of hypertension, eating vegetables and/or fruit daily, khat chewing and smoking. Female participants were also asked if they had a history of gestational diabetes. ${ }^{5,6}$ In the subjects for whom both parents with type $2 \mathrm{DM}$, they were asked if the parents were related, but the exact level of the relation was not requested. The body mass index (BMI) was calculated $\left(\mathrm{kg} / \mathrm{m}^{2}\right)$. Normal BMI was defined as BMI $<25$, overweight as BMI 25-29.99, class I obesity BMI 30-34.99, class II obesity BMI 35-39.99 and class III obesity $\geq 40$ according to the WHO classification. ${ }^{7}$ Waist circumference was measured with a cutoff $\geq 88 \mathrm{~cm}$ for females and $\geq$ $102 \mathrm{~cm}$ for males as a risk factor for cardiometabolic disease. ${ }^{8}$ Blood pressure was measured by the nurse in the clinic using an electronic sphygmomanometer.

The fasting glucose level was drawn in a plain tube, and after centrifugation, it was analyzed on the same day. 
FBG $<100 \mathrm{mg} / \mathrm{dL}$ was considered normal, 100-125 mg/dL IFG and if the FBG was $\geq 126$, the subject was considered to have type 2 diabetes. Subjects with an IFG were requested to undergo a standard oral glucose tolerance test (OGTT) according to ADA criteria (75 gm glucose 2-hour). ${ }^{5}$ The HBA1c was measured in patients who had an $\mathrm{FBG} \geq 126 \mathrm{mg} / \mathrm{dl}$ or in those with IFG if they were unable to submit to an OGTT, if they were from out of town and could not return the next day for an OGTT. A small number of patients $(\mathrm{N}=21)$ opted to undergo an OGTT, and some opted to undergo HBA1c at the same time as the FBG. A level of $<5.7 \%$ was considered normal, $5.7-6.4 \%$ prediabetes and $\geq 6.5 \%$ diabetes as classified by the ADA. ${ }^{5}$ Due to a lack of funding, only the FBG and the clinic visit were free of charge; if the FBG was abnormal, any other work-up, such as OGTT and HBA1c, was performed at the subjects' expense. The FBG was performed on a complimentary basis by MedLabs in Sana'a, Yemen. The study was conducted in accordance with the principles and guidelines of the Declaration of Helsinki for medical research involving human subjects.

\section{Statistical Analysis}

Categorical data are expressed as frequencies and percentages, while numerical variables are described as the means and standard deviations. Chi-square tests, chisquare tests with Yates' correction, Fisher's tests, and binary logistic regression were used to identify the statistical significance of the association between the groups and the outcomes. Variables with a $\mathrm{p}$ value of less than 0.2 were considered in the multiple logistic regression model, which was used to calculate the significance of association, the adjusted OR and 95\% CI using the forward method. All tests with a $\mathrm{p}$ value $<0.05$ were considered statistically significant. SPSS version 26 was used to enter and analyze the data.

\section{Results}

A total of 612 subjects volunteered to participate in the study (196 males and 416 females). The general characteristics of the subjects are shown in Table 1.

The mean age of the subjects was 39.5 (SD $9.595 \% \mathrm{CI}$ 38.8-40.3) and the mean BMI was 32.1 (SD $5.795 \%$ CI 31.6-32.5), with 42.6\% overweight and 57.4\% obese. Among those who were obese, 33.5\% $(\mathrm{N}=205)$ had class I obesity, 14.1\% ( $\mathrm{N}=86)$ had class II obesity and 9.8\% $(\mathrm{N}=60)$ had class III obesity. The majority of the patients had a family history of diabetes in first-degree relatives
(70.1\%) vs $29.9 \%$ with no diabetes in first-degree relatives. Over half of the subjects, 59.3\% ( $\mathrm{N}=363)$, were khat-chewers, and 19.6\% ( $=120)$ were smokers. Only $18.8 \%(\mathrm{~N}=115)$ reported eating fruits or vegetables daily, $34 \%(\mathrm{~N}=208)$ reported doing at least 30 minutes of exercise daily, and $13.6 \%$ had a history of hypertension.

Table 2 shows the different measurements performed on the subjects. A total of $14.7 \%$ had an elevated systolic blood pressure, and $16.5 \%$ had an elevated diastolic blood pressure. The FBG was normal in $55.4 \%(\mathrm{~N}=339)$, and an impaired FBG was found in $34 \%(\mathrm{~N}=208)$. Diabetes was diagnosed when the FBG was $\geq 126 \mathrm{mg} / \mathrm{dl}$, which was found in $10.6 \%(\mathrm{~N}=65)$ of the participants.

In patients with a family history of diabetes, the number of subjects with a normal FBG was lower than those without a family history of diabetes at $52.4 \%(\mathrm{~N}=225)$ vs $62.3 \%(\mathrm{~N}=114)$, but in those with an impaired FBG or an $\mathrm{FBG} \geq 126$, the percentage was higher in the group with a family history of diabetes. In the group with an impaired FBG, 35.9\% (N-154) had a family history of diabetes, $29.5 \%(\mathrm{~N}=54)$ did not, and in the group with an FBG $\geq 126,11.7 \%(\mathrm{~N}=50)$ had a family history of $\mathrm{DM}$, and $8.2 \%(\mathrm{~N}=15)$ had no family history (Table 3$)$.

Subjects who had an IFG were asked to have an OGTT test. In those with a normal FBG, a total of 17 patients had an OGTT, $58.8 \%$ were normal, $23.5 \%$ had an impaired OGTT, and $17.6 \%$ were diabetic. Among those with an IFG, 96 of the subjects had an OGTT, although it was requested for all patients; some never returned for the OGTT or HBA1c $(\mathrm{N}=30)$, some of the patients had an HBA1c instead of an OGTT if they were from out of town and could not return the next day for an OGTT $(\mathrm{N}=80)$, and 2 patients could not be contacted regarding their abnormal FBG results.

Figure 1 shows more details on the prevalence of impaired FBS and type 2 DM, and is clear that type 2 DM in siblings was associated with a higher percentage of type $2 \mathrm{DM}$ in the subjects $(19.1 \%)$ in comparison to 1 parent $(9.1 \%)$ or 2 parents $(9.5 \%)$ with type 2 DM. In the subjects who had both related parents and siblings with diabetes, the percentage of subjects with type 2 DM increased to $27.8 \%$ ( $p$ value 0.031 ).

In Figure 2, we can see that waist circumference was significantly correlated with BMI, but as indicated in Table 4, it was not significantly correlated with the FBG level ( $p$ value 0.933 for prediabetes and 0.548 for diabetes). 
Table I Characteristics of the Patients $(N=6 / 2)$

\begin{tabular}{|c|c|c|c|c|}
\hline Variable & $\begin{array}{l}\text { Mean } \\
\text { (SD) }\end{array}$ & $\begin{array}{c}95 \% \mathrm{Cl} \text { of } \\
\text { Mean }\end{array}$ & $\mathbf{N}$ & $\%$ \\
\hline Age (year) & $39.5(9.5)$ & $38.8-40.3$ & & \\
\hline $20-29$ & & & 77 & 12.6 \\
\hline $30-39$ & & & 254 & 41.5 \\
\hline $40-49$ & & & 178 & 29.1 \\
\hline$\geq 50$ & & & 103 & 16.8 \\
\hline \multicolumn{5}{|l|}{ Sex } \\
\hline Male & & & 196 & 32.0 \\
\hline Female & & & 416 & 68.0 \\
\hline \multicolumn{5}{|l|}{ Exercise } \\
\hline Yes & & & 208 & 34.0 \\
\hline No & & & 404 & 66.0 \\
\hline \multicolumn{5}{|l|}{ Fruit and vegetable intake } \\
\hline Yes & & & 115 & 18.8 \\
\hline No & & & 497 & 81.2 \\
\hline \multicolumn{5}{|l|}{ Khat chewing } \\
\hline Yes & & & 363 & 59.3 \\
\hline No & & & 249 & 40.7 \\
\hline \multicolumn{5}{|l|}{ Smoking } \\
\hline Yes & & & 120 & 19.6 \\
\hline No & & & 492 & 80.4 \\
\hline Height $(\mathrm{cm})$ & I58.4 (8.8) & |57.7-|59.| & & \\
\hline Weight (kg) & $80.4(15.0)$ & $79.2-81.6$ & & \\
\hline BMI $\left(\mathrm{kg} / \mathrm{m}^{2}\right)$ & $32.1(5.7)$ & $31.6-32.5$ & & \\
\hline Overweight & & & 261 & 42.6 \\
\hline Class I obesity & & & 205 & 33.5 \\
\hline Class II obesity & & & 86 & 14.1 \\
\hline Class III obesity & & & 60 & 9.8 \\
\hline Waist circumference $(\mathrm{cm})$ & $98.4(11.4)$ & $97.5-99.3$ & & \\
\hline$F<88, M<102$ & & & 199 & 32.5 \\
\hline$F \geq 88, M \geq 102$ & & & 413 & 67.5 \\
\hline \multicolumn{5}{|l|}{ Gestational DM } \\
\hline Yes & & & 20 & 4.8 \\
\hline No & & & 396 & 95.2 \\
\hline \multicolumn{5}{|l|}{ Parent DM } \\
\hline No DM & & & 230 & 37.6 \\
\hline I parent & & & 262 & 42.8 \\
\hline 2 parents & & & 74 & 12.1 \\
\hline 2 parents related & & & 46 & 7.5 \\
\hline \multicolumn{5}{|l|}{ Sibling DM } \\
\hline Yes & & & 184 & 30.1 \\
\hline No & & & 428 & 69.9 \\
\hline \multicolumn{5}{|l|}{ Family History of DM } \\
\hline \multicolumn{5}{|l|}{ (parents/siblings) } \\
\hline Yes & & & 429 & 70.1 \\
\hline No & & & 183 & 29.9 \\
\hline \multicolumn{5}{|l|}{ Hypertension } \\
\hline Yes & & & 83 & 13.6 \\
\hline No & & & 529 & 86.4 \\
\hline
\end{tabular}

In Table 4, the univariate analysis of the different risk factors for prediabetes and diabetes is shown. There was no significant difference between females and males
Table 2 Parameters Measured in Patients

\begin{tabular}{|c|c|c|c|c|}
\hline Variable & Mean (SD) & $95 \% \mathrm{Cl}$ of Mean & $\mathbf{N}$ & $\%$ \\
\hline Systolic BP & $119.2(18.2)$ & $117.8-120.7$ & & \\
\hline$(\mathrm{mmHg})$ & & & & \\
\hline$\geq 140$ & & & 90 & 14.7 \\
\hline$<140$ & & & 522 & 85.3 \\
\hline Diastolic BP & 77.0 (II.7) & $76.1-78.0$ & & \\
\hline$(\mathrm{mmHg})$ & & & & \\
\hline$\geq 90$ & & & 101 & 16.5 \\
\hline$<90$ & & & 511 & 83.5 \\
\hline FBS (mg/dL) & $102.4(27.5)$ & $100.2-104.6$ & & \\
\hline$<100$ & & & 339 & 55.4 \\
\hline $100-125$ & & & 208 & 34.0 \\
\hline$>125$ & & & 65 & 10.6 \\
\hline RBS (mg/dL) & $174.7(86.3)$ & $156.0-193.4$ & & \\
\hline$<140$ & & & 31 & 36.9 \\
\hline $140-200$ & & & 34 & 40.5 \\
\hline$>200$ & & & 19 & 22.6 \\
\hline Not done & & & 528 & \\
\hline \multicolumn{5}{|l|}{ GTT } \\
\hline Normal & & & 51 & 43.6 \\
\hline Impaired & & & 41 & 35.0 \\
\hline Diabetes & & & 21 & 17.9 \\
\hline Not done & & & 4 & 3.4 \\
\hline Hbalc (\%) & $6.5(1.4)$ & $6.2-6.7$ & & \\
\hline$<5.7$ & & & 28 & 18.8 \\
\hline $5.7-6.4$ & & & 69 & 46.3 \\
\hline$\geq 6.5$ & & & 52 & 34.9 \\
\hline Not done & & & 463 & \\
\hline
\end{tabular}

Table 3 Family History of DM and FBS Level

\begin{tabular}{|c|c|c|c|c|c|}
\hline \multirow{2}{*}{ Variable } & \multicolumn{2}{|c|}{$\begin{array}{c}\text { DM in Parents/ } \\
\text { Sibling }\end{array}$} & \multicolumn{2}{|c|}{$\begin{array}{c}\text { No DM in Parents/ } \\
\text { Sibling }\end{array}$} & \multirow{2}{*}{ P value } \\
\cline { 2 - 5 } & N & $\%$ & N & $\%$ & \\
\hline FBG (mg/dL) & & & & & \multirow{2}{*}{0.073} \\
$<100$ & 225 & 52.4 & 114 & 62.3 & \\
$100-125$ & 154 & 35.9 & 54 & 29.5 & \\
$>125$ & 50 & 11.7 & 15 & 8.2 & \\
\hline
\end{tabular}

regarding pre-DM and DM, although DM was higher in males but did not reach clinical significance ( $p$ value 0.078). A significant risk for DM was found in the age group 40-49 years old and in those with a history of hypertension.

Multivariate regression analyses were performed to examine the association of age, khat chewing, class III obesity and sibling DM and hypertension with pre-DM and DM (Table 5). When adjusted for all other variables, 


\section{Normal FBS $=$ Pre-DM $=\mathrm{DM}$}

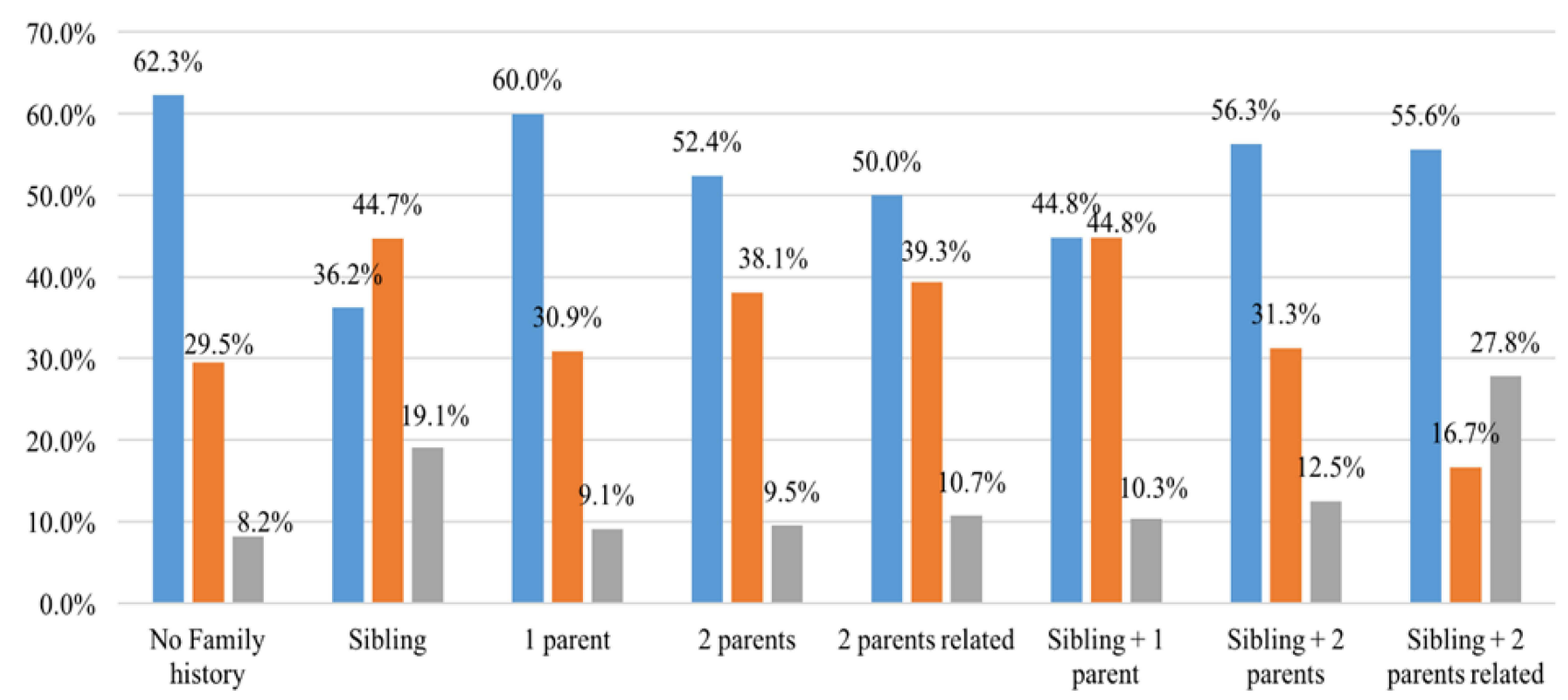

Figure I Prevalence of pre-DM and DM in relation to family history and consanguinity. The figure shows the percentage of subjects with prediabetes and diabetes in relation to the number of first-degree relatives with diabetes in addition to the presence of consanguinity ( $p$ value $0.03 \mathrm{I}$ ).

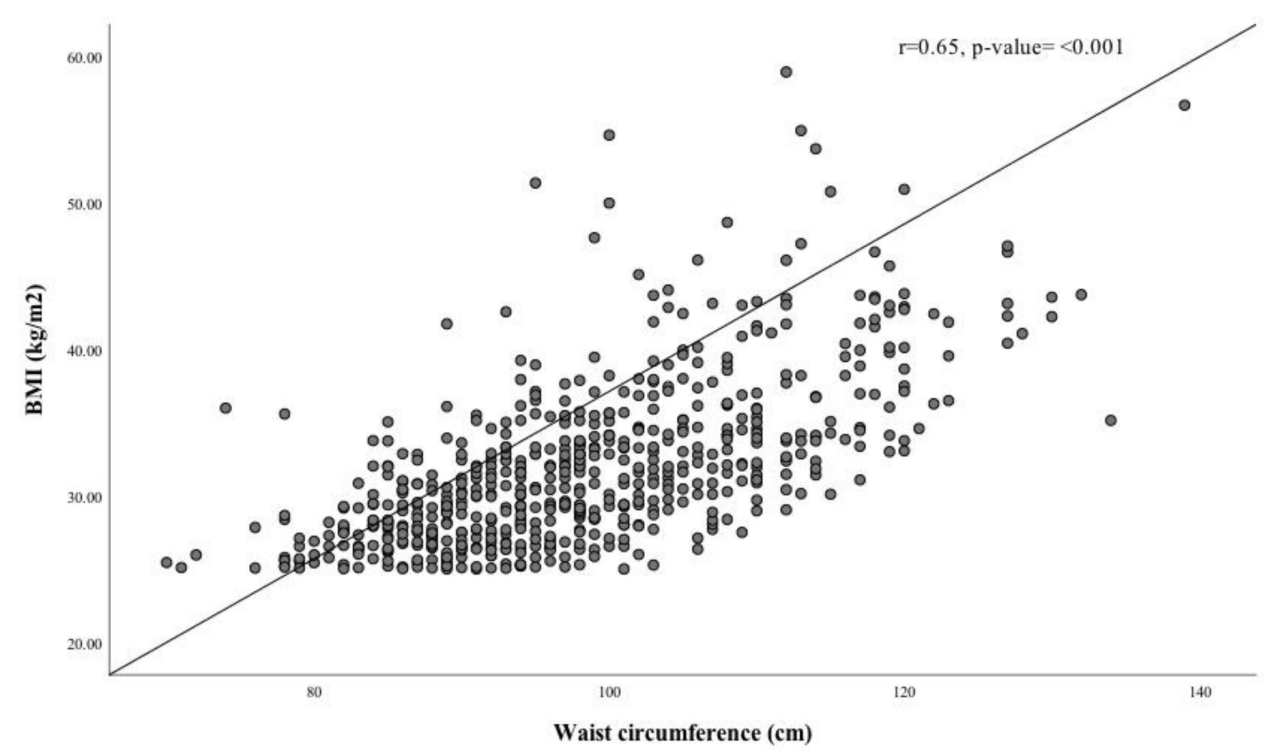

Figure 2 Waist circumference was significantly correlated with BMI $r=0.65$ ( $P$ value $<0.00 \mathrm{I}$ ).

we observed that age (30-39 years) AOR 0.62 (95\% CI 0.4-0.96), khat-chewing AOR 1.61 (95\% CI 1.04-2.48), Class III obesity AOR 3.10 (95\% CI 1.56-6.18) and history of DM in siblings AOR 1.72 (95\% CI 1.09-2.71) were all significant risk factors for the development of preDM. Significant risk factors for the development of DM included age (40-49 years) AOR 1.82 (95\% CI 1.0-3.33), khat-chewing AOR 2.09 (95\% CI 1.14-3.82), Class III obesity AOR 3.35 (95\% CI 1.47-7.65), sibling DM AOR 2.24 (95\% CI 1.25-4.00) and hypertension AOR 3.64 (95\% CI 1.84-7.18).

\section{Discussion}

The results of our study show that among overweight and obese Yemeni adults aged $20-70$ years, the prevalence of prediabetes was $34 \%$, and $10.6 \%$ had diabetes according to 
Table 4 Univariate Analysis Showing Risk Factors for Pre-DM and DM*

\begin{tabular}{|c|c|c|c|c|c|c|c|c|c|c|c|c|c|}
\hline \multirow[t]{2}{*}{ Variable } & \multirow[t]{2}{*}{ Total } & \multicolumn{2}{|c|}{ Normal } & \multicolumn{5}{|c|}{ Pre-DM } & \multicolumn{5}{|c|}{ DM } \\
\hline & & $\mathbf{N}$ & $\%$ & $\mathbf{N}$ & $\%$ & $p$ value & OR & $95 \% \mathrm{Cl}$ & $\mathbf{N}$ & $\%$ & $p$ value & OR & $95 \% \mathrm{Cl}$ \\
\hline \multicolumn{14}{|l|}{ Age (years) } \\
\hline $20-29$ & 77 & 46 & 59.7 & 27 & 35.1 & & 1.00 & & 4 & 5.2 & & 1.00 & \\
\hline $30-39$ & 254 & 159 & 62.6 & 70 & 27.6 & 0.307 & 0.75 & $0.43-1.30$ & 25 & 9.8 & 0.294 & 1.81 & $0.60-5.46$ \\
\hline $40-49$ & 178 & 81 & 45.5 & 74 & 41.6 & 0.128 & 1.56 & $0.88-2.75$ & 23 & 12.9 & 0.039 & 3.27 & $1.06-10.03$ \\
\hline$\geq 50$ & 103 & 53 & 51.5 & 37 & 35.9 & 0.592 & 1.19 & $0.63-2.24$ & 13 & 12.6 & 0.087 & 2.82 & $0.86-9.26$ \\
\hline \multicolumn{14}{|l|}{ Sex } \\
\hline Male & 196 & 103 & 52.6 & 66 & 33.7 & $0.74 I$ & 1.07 & $0.73-1.55$ & 27 & 13.8 & 0.078 & 1.63 & $0.94-2.81$ \\
\hline Female & 416 & 236 & 56.7 & 142 & 34.1 & & 1.00 & & 38 & 9.1 & & 1.00 & \\
\hline \multicolumn{14}{|l|}{ Exercise } \\
\hline Yes & 208 & 117 & 56.3 & 72 & 34.6 & 0.981 & 1.01 & $0.70-1.44$ & 19 & 9.1 & 0.409 & 0.78 & $0.44-1.40$ \\
\hline No & 404 & 222 & 55.0 & 136 & 33.7 & & 1.00 & & 46 & 11.4 & & 1.00 & \\
\hline \multicolumn{14}{|c|}{ Fruit and vegetable intake } \\
\hline Yes & 115 & 64 & 55.7 & 37 & 32.2 & 0.750 & 0.93 & $0.59-1.46$ & 14 & 12.2 & 0.619 & 1.18 & $0.62-2.26$ \\
\hline No & 497 & 275 & 55.3 & $|7|$ & 34.4 & & 1.00 & & 51 & 10.3 & & 1.00 & \\
\hline \multicolumn{14}{|l|}{ Khat chewing } \\
\hline Yes & 363 & 187 & 51.5 & 130 & 35.8 & 0.091 & 1.36 & $0.95-1.93$ & 46 & 12.7 & 0.020 & 1.97 & $1.11-3.50$ \\
\hline No & 249 & 152 & 61.0 & 78 & 31.3 & & 1.00 & & 19 & 7.6 & & 1.00 & \\
\hline \multicolumn{14}{|l|}{ Smoking } \\
\hline Yes & 120 & 63 & 52.5 & 44 & 36.7 & 0.462 & 1.18 & $0.76-1.81$ & 13 & 10.8 & 0.789 & 1.10 & $0.56-2.13$ \\
\hline No & 492 & 276 & 56.1 & 164 & 33.3 & & 1.00 & & 52 & 10.6 & & 1.00 & \\
\hline \multicolumn{14}{|l|}{ BMI $(\mathrm{kg} / \mathrm{m} 2)$} \\
\hline Overweight & 261 & 145 & 55.6 & 92 & 35.2 & & 1.00 & & 24 & 9.2 & & 1.00 & \\
\hline Class I obesity & 205 & 116 & 56.6 & 70 & 34.1 & 0.804 & 0.95 & $0.64-|.4|$ & 19 & 9.3 & 0.975 & 0.99 & $0.52-1.90$ \\
\hline Class II obesity & 86 & 57 & 66.3 & 18 & 20.9 & 0.021 & 0.50 & $0.28-0.90$ & 11 & 12.8 & 0.698 & 1.17 & $0.54-2.54$ \\
\hline Class III obesity & 60 & 21 & 35.0 & 28 & 46.7 & 0.020 & 2.10 & $1.13-3.92$ & 11 & 18.3 & 0.008 & 3.17 & $1.36-7.39$ \\
\hline \multicolumn{14}{|c|}{ Waist circumference $(\mathrm{cm})$} \\
\hline$F<88, M<102$ & 199 & 112 & 56.3 & 68 & 34.2 & 0.933 & 0.98 & $0.68-1.422$ & 19 & 9.5 & 0.548 & 0.84 & $0.47-1.50$ \\
\hline$F \geq 88, M \geq 102$ & 413 & 227 & 55.0 & 140 & 33.9 & & 1.00 & & 46 & II.I & & 1.00 & \\
\hline \multicolumn{14}{|l|}{ Gestational DM } \\
\hline Yes & 20 & 8 & 40.0 & 9 & 45.0 & 0.180 & 1.93 & $0.73-5.12$ & 3 & 15.0 & 0.386 & 2.44 & $0.62-9.65$ \\
\hline No & 396 & 228 & 57.6 & 133 & 33.6 & & 1.00 & & 35 & 8.8 & & 1.00 & \\
\hline \multicolumn{14}{|l|}{ Parent DM } \\
\hline No DM & 230 & $13 \mid$ & 57.0 & 75 & 32.6 & & 1.00 & & 24 & 10.4 & & 1.00 & \\
\hline I parent & 262 & 144 & 55.0 & 93 & 35.5 & 0.540 & 1.13 & $0.77-1.66$ & 25 & 9.5 & 0.862 & 0.95 & $0.52-1.74$ \\
\hline 2 parents & 74 & 40 & 54.1 & 26 & 35.1 & 0.662 & 1.14 & $0.64-2.01$ & 8 & 10.8 & 0.844 & 1.09 & $0.46-2.62$ \\
\hline 2 parents related & 46 & 24 & 52.2 & 14 & 30.4 & 0.959 & 1.02 & $0.50-2.09$ & 8 & 17.4 & 0.198 & 1.82 & $0.73-4.52$ \\
\hline Sibling DM & & & & & & 1.019 & & & & & & & \\
\hline Yes & 184 & 84 & 45.7 & 73 & 39.7 & 0.010 & 1.64 & $1.13-2.39$ & 27 & 14.7 & 0.006 & 2.16 & $1.24-3.74$ \\
\hline No & 428 & 255 & 59.6 & 135 & 31.5 & & 1.00 & & 38 & 8.9 & & 1.00 & \\
\hline Family history of DM & & & & & & 1.642 & & & & & & & \\
\hline Yes & 429 & 225 & 52.4 & 154 & 35.9 & 0.059 & 1.45 & $0.99-2.12$ & 50 & 11.7 & 0.095 & 1.69 & $0.91-3.14$ \\
\hline No & 183 & 114 & 62.3 & 54 & 29.5 & & 1.00 & & 15 & 8.2 & & 1.00 & \\
\hline \multicolumn{14}{|l|}{ Hypertension } \\
\hline Yes & 83 & 35 & 42.2 & 30 & 36.1 & 0.150 & 1.46 & $0.87-2.47$ & 18 & 21.7 & $<0.001$ & 3.33 & $1.74-6.35$ \\
\hline No & 529 & 304 & 57.5 & 178 & 33.6 & & 1.00 & & 47 & 8.9 & & 1.00 & \\
\hline \multicolumn{14}{|l|}{ Systolic BP (mmHg) } \\
\hline$\geq 140$ & 90 & 42 & 46.7 & 34 & 37.8 & 0.194 & 1.38 & $0.85-2.25$ & 14 & 15.6 & 0.051 & 1.94 & $0.99-3.81$ \\
\hline$<140$ & 522 & 297 & 56.9 & 174 & 33.3 & & 1.00 & & 51 & 9.8 & & 1.00 & \\
\hline
\end{tabular}

(Continued) 
Table 4 (Continued).

\begin{tabular}{|c|c|c|c|c|c|c|c|c|c|c|c|c|c|}
\hline \multirow[t]{2}{*}{ Variable } & \multirow[t]{2}{*}{ Total } & \multicolumn{2}{|c|}{ Normal } & \multicolumn{5}{|c|}{ Pre-DM } & \multicolumn{5}{|c|}{ DM } \\
\hline & & $\mathbf{N}$ & $\%$ & $\mathbf{N}$ & $\%$ & $p$ value & OR & $95 \% \mathrm{Cl}$ & $\mathbf{N}$ & $\%$ & $p$ value & OR & $95 \% \mathrm{Cl}$ \\
\hline \multicolumn{14}{|l|}{ Diastolic BP (mmHg) } \\
\hline$\geq 90$ & 101 & 50 & 49.5 & 34 & 33.7 & 0.615 & 1.13 & $0.70-1.82$ & 17 & 16.8 & 0.024 & 2.05 & $1.09-3.84$ \\
\hline$<90$ & 511 & 289 & 56.6 & 174 & 34.1 & & 1.00 & & 48 & 9.4 & & 1.00 & \\
\hline GTT & & & & & & 1.129 & & & & & & & \\
\hline Normal & 51 & 10 & 19.6 & 41 & 80.4 & & 1.00 & & 0 & 0.0 & & 1.00 & \\
\hline Impaired & 41 & 4 & 9.8 & 35 & 85.4 & 0.232 & 2.13 & $0.62-7.41$ & 2 & 4.9 & & - & \\
\hline Diabetes & 21 & 3 & 14.3 & 16 & 76.2 & 0.715 & 1.30 & $0.32-5.35$ & 2 & 9.5 & & - & \\
\hline Not done & 4 & 0 & 0.0 & 4 & 100.0 & 0.999 & - & & 0 & 0.0 & & - & \\
\hline Hbalc (\%) & & & & & & 1.301 & & & & & & & \\
\hline$<5.7$ & 28 & 9 & 32.1 & 17 & 60.7 & & 1.00 & & 2 & 7.1 & & 1.00 & \\
\hline $5.7-6.4$ & 69 & 11 & 15.9 & 41 & 59.4 & 0.203 & 1.97 & $0.69-5.62$ & 17 & 24.6 & 0.026 & 6.96 & $1.26-38.44$ \\
\hline$\geq 6.5$ & 52 & 0 & 0.0 & 22 & 42.3 & 0.998 & - & & 30 & 57.7 & 0.998 & - & \\
\hline
\end{tabular}

Note: * P-value and OR were calculated for Pre-DM and DM patients separately against the Normal.

Table 5 Multivariate Analysis of Risk Factors for Pre-DM and DM

\begin{tabular}{|l|c|c|c|c|c|c|c|}
\hline Variable & B & S.E. & Wald & P value & \multicolumn{2}{|c|}{ AOR } & \multicolumn{2}{|c|}{$95 \%$ CI } \\
\cline { 3 - 7 } & & & & & & \\
Lre-DM against Normal & & & & & & \\
Age (30-39 years old) & -0.48 & 0.23 & 4.54 & 0.033 & 0.62 & 0.40 & 0.96 \\
Khat chewing & 0.48 & 0.22 & 4.62 & 0.032 & 1.61 & 1.04 & 2.48 \\
Class III obesity & 1.13 & 0.35 & 10.32 & 0.001 & 3.10 & 1.56 & 6.18 \\
Sibling DM & 0.54 & 0.23 & 5.40 & 0.020 & 1.72 & 1.09 & 2.71 \\
DM against Normal & & & & & & \\
Age (40-49 year) & 0.60 & 0.31 & 3.79 & 0.051 & 1.82 & 1.00 & 3.33 \\
Khat chewing & 0.74 & 0.31 & 5.67 & 0.017 & 2.09 & 1.14 & 3.82 \\
Class III obesity & 1.21 & 0.42 & 8.22 & 0.004 & 3.35 & 1.47 & 7.65 \\
Sibling DM & 0.80 & 0.30 & 7.33 & 0.007 & 2.24 & 1.25 & 4.00 \\
Hypertension & 1.29 & 0.35 & 13.80 & $<0.001$ & 3.64 & 1.84 & 7.18 \\
\hline
\end{tabular}

the FBG when using the ADA criteria for diagnosis. Over half of our patients were obese $(57.4 \%)$, and $9.8 \%$ of the patients had class III obesity with a BMI $\geq 40$ according to the WHO classification of obesity. ${ }^{7}$ The group with class III obesity was found to have a significant association with prediabetes ( $\mathrm{p}$ value 0.001 ) and diabetes ( $\mathrm{p}$ value 0.004 ). This is the first study to the best of our knowledge, after searching the literature, to address the prevalence of preDM and DM in overweight and obese Yemeni patients. The last study performed on the prevalence of type $2 \mathrm{DM}$ in Yemen was in 2006 by Gunaid et al, which showed the overall age-standardized prevalence of diabetes to be $6.3 \%$ and for either IFG/IGT to be $9 \%$ for the age range 30-64 years among Yemeni adults. ${ }^{9}$
A recent study performed on Yemeni school-aged children who were 12-13 years old showed that the prevalence of prediabetes as defined by an IFG was $0.86 \% .{ }^{10}$ In neighboring countries such as Saudi Arabia, abnormal glucose metabolism in children and adolescents exceeds $10 \%{ }^{11}$

In our study, we studied high-risk adults who were overweight or obese with a family history of diabetes in first-degree relatives and some with parents with DM and related conditions. According to the ADA criteria, these are people who should be screened at any age. ${ }^{5}$

In our study, in the younger age group, subjects who were often not screened were aged 20-29 years old, 35.1\% had an IFG, and 5.2\% were diabetic. In the 30-39 year-old 
group, the risk of diabetes increased to $9.8 \%$. When compared with other studies in Ethiopia among 20-29 year-old subjects, $1.5 \%$ had IFG, and $1 \%$ had undiagnosed diabetes, but these included all subjects regardless of BMI. ${ }^{12}$ In Iran, among overweight subjects, the prevalence of prediabetes was $31.6 \%$ and diabetes was $16 \%$; in obese subjects aged 20-65 years old, the prevalence of prediabetes was $34.6 \%$ and diabetes was $21.1 \%$; and in the younger age group (20-34.9 years), $26.9 \%$ had prediabetes and $3.5 \%$ had diabetes, which was lower than in our patients, but this result was for all BMIs and regardless of family history. ${ }^{13}$ Another study in Iran showed that first degree relatives of people with type $2 \mathrm{DM}$ who were overweight or obese were at much higher risk of diabetes $(10.2 \%)$ and IFG $(16.6 \%)$ than non-obese relatives in whom the prevalence of diabetes was $(6.8 \%)$ and IFG $(14.8 \%) .{ }^{14}$ Among Kuwaiti adults, prediabetes was found in $47.9 \%$ according to the FBG criteria and $6.9 \%$ had type $2 \mathrm{DM}$ by FBG, this is in a group of subjects who were primarily overweight and obese (43.6\% and $37.1 \%$, respectively). ${ }^{15}$ In a study on adult males in Saudi Arabia in which 32.3\% were overweight and $36.2 \%$ were obese, the prevalence of prediabetes was $27.6 \%$, and the prevalence of diabetes was 9.2\%. ${ }^{16}$ In females in Saudi Arabia, a study showed the crude prevalence of prediabetes to be $18.8 \%$ and diabetes to be $3.8 \%$ in a group of women in whom $23.4 \%$ were overweight and $22.6 \%$ were obese. ${ }^{17}$

A systemic review and meta-analysis of 55 articles on prediabetes and undiagnosed type 2 diabetes in the Eastern Mediterranean region showed that $12.9 \%$ had prediabetes and $5.4 \%$ had diabetes. ${ }^{18}$ Our patients were all overweight and obese, and in those with one first degree relative or more, the risk of prediabetes and diabetes was very high, at $47.6 \%$. In those with siblings with diabetes, the risk was higher than for those with both parents with diabetes $(19.1 \%$ vs, 9.5\%). Other studies have also shown that in subjects with siblings having a history of type 2 diabetes, the risk of developing diabetes was higher than in those who had parents who were diabetic. ${ }^{19,20}$ The majority of the adults who volunteered to participate in our study were spouses, siblings and offspring of patients with DM. Another study has shown that spouses of patients with DM were at higher risk of having diabetes than those whose spouses did not have diabetes. ${ }^{21}$

Consanguinity and a family history of diabetes among parents has also been shown to increase the risk of prediabetes in Pakistan and in other studies in Qatar and Saudi Arabia. ${ }^{22-24}$ Consanguinity has also been found to be a risk factor for obesity, which is a multifactorial/heterogeneous disease that leads to medical complications such as type $2 \mathrm{DM}^{25}$ Genetic studies have shown ACE gene polymorphism through allele frequencies to be associated with obesity in the offspring of consanguineous first cousins in Saudi Arabia. ${ }^{26}$

Consanguinity is common in Yemen and was shown to have an incidence of $44.7 \%$ in Sana'a, with $71.6 \%$ being first cousin marriages and $32 \%$ being all marriages. ${ }^{27}$ In our study, we asked if the parents were related but did not ask the degree of relation between them, but we still found that those with both parents with DM and related parents, the prevalence of diabetes was higher than if not related. In addition, if the siblings had DM, the prevalence of diabetes increased to $27.8 \%$ in this group ( $p$ value 0.031 ).

Khat chewing was significantly correlated with increased prediabetes and diabetes in our patients, with over half of our subjects being khat chewers (59.3\%). In Yemen, it is a common belief among our patients who khat chewing has a beneficial effect on DM. ${ }^{24}$ Khat chewing has been shown to be a risk factor for developing type 2 DM at a younger age in a study in Yemen and increased the risk of diabetes in a study in Saudi Arabia. ${ }^{28,29}$

Hypertension and diabetes are common diseases, and it is recommended that clinicians screen adults with hypertension and a BMI $\geq 25$ for DM. ${ }^{5}$ In our study, we found hypertension to be significantly correlated with an increased prevalence of diabetes ( $p$ value $<0.001$ ). Other studies have shown similar results. ${ }^{30,31}$

Central obesity or increased waist circumference (WC) has been shown to increase the risk of type $2 \mathrm{DM}$ in many studies. ${ }^{32-34}$ Among our patients, we did not find any significant increase in prediabetes and diabetes among our patients with a WC in females $\geq 88 \mathrm{~cm}$ and in males $\geq 102 \mathrm{~cm}$, as recommended by the American Heart Association as a cutoff for increased risk of diabetes, ${ }^{35}$ but we did find a significant correlation with BMI ( $p$ value $<0.001)$.

Exercise improves blood glucose control in type 2 diabetes, and regular exercise may prevent or delay type 2 diabetes development. ${ }^{36,37}$ Among our patients, only $33.9 \%$ said they exercised for approximately 30 minutes a day, and although the percentage of those with diabetes was slightly higher in the subjects who did not exercise, it did not reach clinical significance $(11.4 \%$ vs $9.1 \%$ p value 0.409 ), which may be because a detailed history regarding exercise was not taken during our study. 
Eating a healthy diet is important for preventing cardiovascular disease, cancer and type $2 \mathrm{DM}$, and fruits and vegetables (not including potatoes) should make up half of a meal. ${ }^{38}$ When the subjects were asked about eating vegetables and fruits, only 115 (18.7\%) said they ate vegetables or fruit on a daily basis, and most of them complained about the cost of fruit with the decreased income due to the war in Yemen. Additionally, many of our patients had limited knowledge about what a healthy diet was.

Class III obesity was significantly correlated with an increase in prediabetes and obesity in our study when compared with those who were overweight. Having a $\mathrm{BMI} \geq 25$ has been associated with an increased risk of prediabetes and diabetes in many studies in the region. ${ }^{39-43}$ We do not have any studies set in Yemen showing the prevalence of obesity among the general population, but among patients with diabetes, it is lower than that of neighboring countries in the gulf. ${ }^{44}$ In 2 previous studies in Yemen, with the first done in 2014, the results showed the prevalence of patients with type $2 \mathrm{DM}$ with a BMI $\geq 25$ to be $58.3 \%$ with $28.8 \%$ being obese. A three-year study published in 2020 did not show a significant increase in obesity among females with type 2 DM from the previous study ( $p$ value 0.117 ), but among the males with type $2 \mathrm{DM}$, the prevalence of obesity increased from $32.3 \%$ to $33 \%$ ( $\mathrm{p}$ value 0.035 ). ${ }^{45,46}$

The strength of our study is that it is the first to show the prevalence of prediabetes and undiagnosed diabetes in overweight and obese Yemeni adults with a family history of diabetes. Our study shows that in Yemeni adults who are overweight and obese, screening should start at an early age, because these adults are at high risk of developing prediabetes and diabetes. In adults with first-degree relatives who have type $2 \mathrm{DM}$, consanguinity of the parents, siblings with type 2 $\mathrm{DM}$, khat chewers, and those a history of hypertension are at high risk for developing diabetes in the future. The limitations of our study are that it was performed on a high-risk group, and larger studies in the general population, including those with a normal BMI, must be performed to measure the overall prevalence in Yemen, including people from different areas of Yemen. In our study, we depended primarily on FBG to diagnose adults with prediabetes and diabetes, with only a small number undergoing an OGTT or HBA1c due to a lack of funding.

\section{Conclusion}

In conclusion, our study showed that there is a high prevalence of prediabetes and undiagnosed type $2 \mathrm{DM}$ among overweight and obese Yemeni adults, with the risk being highest in those with class III obesity, and in those with first-degree relatives, especially for those with siblings and consanguinous parents with DM, the risk was high. Other risk factors included khat chewing, hypertension, and being in the 30-39-year-old age group for prediabetes and 40-49 years old for diabetes. Further studies are needed regarding consanguinity and khat chewing and the relation to pre-DM and type $2 \mathrm{DM}$ in larger populations, including adults with normal weight. Education of doctors and the general population about screening overweight and obese adults at any age can lead to early detection, and interventions in the group with prediabetes can prevent progression to diabetes. Early detection and treatment of diabetes can help prevent the development of complications in these patients.

\section{Data Sharing Statement}

The data used to support the findings of this study are available from the corresponding author upon request.

\section{Ethics Approval and Informed Consent}

This study was approved by the ethical committee at the University of Science and Technology Hospital. Written informed consent was obtained from all the study participants.

\section{Acknowledgments}

We wish to thank Professor Abdullah A. Gunaid for his guidance and advice and Dr. Farouk Al-Qadasi for performing the statistical analysis. Additionally, we would like to thank the nurses in the clinics who helped measure the blood pressure, heights and weights of the participants. We also wish to thank all the participants who had blood work performed on their own expense and brought back the results to our clinic, and we wish to thank the MedLabs laboratory for performing the complimentary FBG for all the participants we sent to them.

\section{Disclosure}

The authors declare that they have no conflicts of interest in this work.

\section{References}

1. Ali Khan I. Do second generation sequencing techniques identify documented genetic markers for neonatal diabetes mellitus? Heliyon. 2021;7(9):e07903. PMID: 34584998; PMCID: PMC8455689. doi:10.1016/j.heliyon.2021.e07903 
2. Alharbi KK, Abudawood M, Khan IA. Amino-acid amendment of Arginine-325-Tryptophan in rs13266634 genetic polymorphism studies of the SLC30A8 gene with type 2 diabetes-mellitus patients featuring a positive family history in the Saudi population. $J$ King Saud Univ Sci. 2021;33(1):101258. doi:10.1016/j.jksus.2020.101258

3. International Diabetes Federation. IDF Diabetes Atlas. 9th ed. Brussels, Belgium: International Diabetes Federation; 2019.

4. Beagley J, Guargiguata L, Weil C, Motala AA. Global estimates of undiagnosed diabetes in adults. Diabetes Res Clin Pract. 2014;103 (2):150-160. doi:10.1016/j.diabres.2013.11.001

5. American Diabetes Association. 2. Classification and diagnosis of diabetes: standards of medical care in Diabetes-2021. Diabetes Care. 2021;44(Supplement 1):S15. doi:10.2337/dc21-S002

6. Schwarz PE, Schwarz J, Schuppenies A, Bornstein SR, Schulze J. Development of a diabetes prevention management program for clinical practice. Public Health Rep. 2007;122(2):258-263. PMID: 17357369; PMCID: PMC1820432. doi:10.1177/003335490712 200216

7. World Health Organization. Obesity: preventing and managing the global epidemic. Report of a WHO consultation. World Health Organization technical report series; 2000:894i.

8. Jensen MD, Ryan DH, Apovian CM, et al. AHA/ACC/TOS guideline for the management of overweight and obesity in adults: a report of the American College of Cardiology/American Heart Association task force on practice guidelines and the obesity society. Circulation. 2013;2014(129):S102.

9. Gunaid AA, Assabri AM. Prevalence of type 2 diabetes and other cardiovascular risk factors in a semirural area in Yemen. East Mediterr Health J. 2006;14:1.

10. Saeed W, Al-Habori M, Saif-Ali R, Al-Eryani E. Metabolic syndrome and prediabetes among Yemeni school-aged children. Diabetes Metab Syndr Obes. 2020;13:2563-2572. doi:10.2147/DMSO.S260131

11. Al-Rubeaan K. National surveillance for type 1, type 2 diabetes and prediabetes among children and adolescents: a population based study (Saudi-DM). J Epidemiol Community Health. 2015;69 (11):1045-1051. doi:10.1136/jech-2015-205710

12. Worede A, Alemu S, Gelaw YA, Abebe M. the prevalence of impaired fasting glucose and undiagnosed diabetes mellitus and associated risk factors among adults living in a rural Koladiba town, northwest Ethiopia. BMC Res Notes. 2017;10(1):251. doi:10.1186/s13104-017-2571-3

13. Hariri S, Rahimi Z, Hashimi-Madani N, et al. Prevalence and determinants of diabetes and prediabetes in southwestern Iran: the Khuzestan comprehensive health study (KCHS). BMC Endocr Disord. 2021;21(1):135. doi:10.1186/s12902-021-00790-x

14. Amini M, Janghorbani M. Diabetes and impaired glucose regulation in first-degree relatives of patients with type 2 diabetes in Isfahan, Iran: prevalence and risk factors. Rev Diabet Stud. 2007;4 (3):169-176. doi:10.1900/RDS.2007.4.169

15. Mohammed A, Ziyab AH, Mohammed T. Prevalence of prediabetes and undiagnosed diabetes among Kuwaiti adults: a cross-sectional study. Diabetes Metab Syndr Obes. 2021;14:2167-2176. doi:10.2147/ DMSO.S296848

16. Aldossari KK, Aldiab A, Al-Zahrani JM, et al. Prevalence of prediabetes, diabetes and its associated risk factors among males in Saudi Arabia: a population based survey. $J$ Diabetes Res. 2018;2018:2194604. doi:10.1155/2018/2194604

17. Al-Zahrani JM, Aldiab A, Aldossari KK, et al. Prevalence of prediabetes, diabetes and its predictors among females in Alkharj, Saudi Arabia: a cross-sectional study. Ann Glob Health. 2019;85(1):1-13. doi: $10.5334 / \operatorname{aogh} .2467$

18. Mirahmadizadeh A, Fathalipour M, Mokhtari AM, Zeighami S, Hassanipour S, Heiran A. The prevalence of undiagnosed type 2 diabetes and prediabetes in Eastern Mediterranean region (EMRO): a systematic review and meta-analysis. Diabetes Res Clin Pract. 2020;160:107931. doi:10.1016/j.diabres.2019.107931
19. Chiu H, Lee MY, Wu PY, Huang JC, Chen SC, Chang JM. Comparison of the effects of sibling and parental history of type 2 diabetes on metabolic syndrome. Sci Rep. 2020;10(1):22131. doi:10.1038/s41598-020-79382-z

20. Chein KL, Hsu JC, Su TC, et al. Sibling and parental history in type 2 diabetes risk among ethnic Chinese: the Chin-Shan community cardiovascular cohort study. Eur J Cardiovasc Prev Rehabil. 2008;15 (6):657-662. doi:10.1097/HJR.0b013e32830fe451

21. Sun J, Lu J, Wang W, et al. Prevalence of diabetes and cardiometabolic disorders in spouses of diabetic individuals. Am J Epidemiol. 2016;184(5):400-409. doi:10.1093/aje/kwv330

22. Shahid A, Saeed S, Rana S, Mahmood S. Family history of diabetes and parental consanguinity: important risk for impaired fasting glucose in South East Asians. West Indian Med J. 2012;61(3):219. doi:10.7727/wimj.2011.072

23. Bener A, Hussain R, Teebi AS. Consanguineous marriages and their effect on common diseases: studies from an endogamous population. Med Princ Pract. 2007;16(4):262-267. doi:10.1159/000102147

24. Gosadi IM, Goyder EC, Teare MD. Investigating the potential effect of consanguinity on type 2 diabetes susceptibility in a Saudi Population. Hum Hered. 2014;77(1-4):197-206. doi:10.1159/000362447

25. Alharbi KK, Al-Sheikh YA, Alsaadi MM, et al. Screening for obesity in the offspring of first-cousin consanguineous couples: a phase-I study in Saudi Arabia. Saudi J Biol Sci. 2020;27(1):242-246. PMID: 31889843; PMCID: PMC6933162. doi:10.1016/j.sjbs.2019.09.001

26. Alshammary AF, Khan IA. Screening of obese offspring of first-cousin consanguineous subjects for the angiotensin-converting enzyme gene with a 287-bp Alu sequence. J Obes Metab Syndr. 2021;30(1):63-71. PMID: 33653971; PMCID: PMC8017326. doi:10.7570/jomes20086

27. Gunaid AA, Hummad NA, Tamim KA. Consanguineous marriage in the capital city Sana'a Yemen. J Biosoc Sci. 2004;36(1):111-121. doi:10.1017/S0021932003006138

28. Al-Sharafi BA, Gunaid AA. Effect of Habitual khat chewing on glycemic control, body mass index, and age at diagnosis of diabetes in patients with type 2 diabetes in Yemen. Clin Med Insights Endocrinol Diabetes. 2015;8:47-53.

29. Badedi M, Darraj H, Hummadi A, et al. Khat chewing and type 2 diabetes mellitus. Diabetes Metab Syndr Obes. 2020;13:307-312. doi:10.2147/DMSO.S240680

30. Brož J, Malinovská J, Nunes MA, et al. Prevalence of diabetes and prediabetes and its risk factors in adults aged 25-64 in the Czech Republic: a cross-sectional study. Diabetes Res Clin Pract PMID: 32998019. 2020;170:108470. doi:10.1016/j.diabres.2020.108470

31. Satman I, Omer B, Tutuncu Y, et al.; TURDEP-II Study Group. Twelve-year trends in the prevalence and risk factors of diabetes and prediabetes in Turkish adults. Eur J Epidemiol. 2013;28 (2):169-180. PMID: 23407904; PMCID: PMC3604592. doi:10.1007/s10654-013-9771-5

32. Wang Y, Rimm EB, Stampfer MJ, Willett WC, Hu FB. Comparison of abdominal adiposity and overall obesity in predicting risk of type 2 diabetes among men. Am J Clin Nutr. 2005;81(3):555-563. PMID: 15755822. doi:10.1093/ajen/81.3.555

33. Siddiquee T, Bhowmik B, Karmaker RK, et al. Association of general and central obesity with diabetes and pediabetes in rural Bangladeshi population. Diab Met Syndr Clin Res Rev. 2015;9(4):247-251. doi:10.1016/j.dsx.2015.02.002

34. Haghighatdoost F, Amini M, Feizi A, Iraj B. Are body mass index and waist circumference significant predictors of diabetes and prediabetes risk: results from a population based cohort study. World $J$ Diabetes. 2017;8(7):365-373. PMID: 28751960; PMCID: PMC5507834. doi:10.4239/wjd.v8.i7.365

35. Jensen MD, Ryan DH, Apovian CM, et al. AHA/ACC/TOC guideline for the management of overweight and obesity in adults: a report of the American College of Cardiology /American Heart Association task force on practice guidelines and the obesity society. Circulation. 2014;129(Suppl 2):S102. doi:10.1161/01.cir.0000437739.71477.ee 
36. Colberg SR, Sigal RJ, Yardley JE, et al. Physical activity/exercise and diabetes: a position statement of the American Diabetes Association. Diabetes Care. 2016;39(11):2065-2079. PMID: 27926890; PMCID PMC6908414. doi:10.2337/dc16-1728

37. Schellenberg ES, Dryden DM, Vandermeer B, Ha C, Korownyk C. Lifestyle interventions for patients with and at risk for type 2 diabetes: a systematic review and meta-analysis. Ann Intern Med. 2013;159 (8):543-551. doi:10.7326/0003-4819-159-8-201310150-00007

38. Locke A, Schneiderhan J, Zick SM. Diets for health: goals and guidelines. Am Fam Physician. 2018;97(11):721-728. PMID: 30215930.

39. Aljulifi MZ. Prevalence and reasons of increased type 2 diabetes in Gulf Cooperation Council Countries. Saudi Med J. 2021;42(5):481-490. PMID: 33896777. doi:10.15537/smj.2021.42.5.20200676

40. Alhyas L, McKay A, Majeed A. Prevalence of type 2 diabetes in the States of the co-operation council for the Arab States of the Gulf: a systematic review. PLoS One. 2012;7(8):e40948. PMID: 22905094; PMCID: PMC3414510. doi:10.1371/journal.pone.0040948

41. Alhyas L, McKay A, Balasanthiran A, Majeed A. Prevalences of overweight, obesity, hyperglycaemia, hypertension and dyslipidaemia in the Gulf: systematic review. JRSM Short Rep. 2011;2(7):55. PMID: 21847437; PMCID: PMC3147233. doi:10.1258/shorts.2011.011019
42. Hamoudi R, Saheb Sharif-Askari N, Saheb Sharif-Askari F, et al. Prediabetes and diabetes prevalence and risk factors comparison between ethnic groups in the United Arab Emirates. Sci Rep. 2019;9(1):17437. PMID: 31767874; PMCID: PMC6877520. doi:10.1038/s41598-019-53505-7

43. Siddiquee T, Bhowmik B, Karmaker RK, et al. Association of general and central obesity with diabetes and prediabetes in rural Bangladeshi population. Diabetes Metab Syndr. 2015;9(4):247-251. PMID: 25795165. doi: 10.1016/j.dsx.2015.02.002

44. Abuyassin B, Laher I. Obesity-linked diabetes in the Arab world: a review. East Mediterr Health J. 2015;21(6):420-439. PMID: 26370001. doi:10.26719/2015.21.420

45. A1-Sharafi BA, Gunaid AA. Prevalence of obesity in patients with type 2 diabetes mellitus in Yemen. Int J Endocrinol Metab. 2014;12 (2):e13633. doi:10.5812/ijem. 13633

46. Al-Sharafi BA, Algoby MA, Salem K. Glycemic control, medication use and obesity among patients with type 2 diabetes mellitus presenting to an endocrinology clinic during the war in Yemen. A three-year retrospective study. J Diab Res Ther. 2020;6(2). doi:10.16966/23805544

\section{Publish your work in this journal}

Diabetes, Metabolic Syndrome and Obesity: Targets and Therapy is an international, peer-reviewed open-access journal committed to the rapid publication of the latest laboratory and clinical findings in the fields of diabetes, metabolic syndrome and obesity research. Original research, review, case reports, hypothesis formation, expert opinion and commentaries are all considered for publication. The manuscript management system is completely online and includes a very quick and fair peer-review system, which is all easy to use. Visit http://www.dovepress.com/testimonials.php to read real quotes from published authors. 